\title{
Erratum to: Spiritual Wellbeing Mediates PTSD Change in Veterans with Military-Related PTSD
}

\author{
Jill E. Bormann • Lin Liu • Steven R. Thorp • \\ Ariel J. Lang
}

Published online: 21 December 2011

(C) International Society of Behavioral Medicine 2011

Erratum to: Int.J. Behav. Med.

\section{DOI 10.1007/s12529-011-9186-1}

In reference 40 in the original publication, the year and volume publication information is incorrect. The correct reference is:

40. Baron RM, Kenny DA. The moderator-mediator variable distinction in social psychological research: Conceptual, strategic, and statistical considerations. J Pers Soc Psychol. 1986;51:1173-1182.

The online version of the original article can be found at http://dx.doi. org/10.1007/s12529-011-9186-1.

J. E. Bormann · S. R. Thorp · A. J. Lang

Center of Excellence for Stress and Mental Health (CESAMH),

Veterans Affairs San Diego Healthcare System (VASDHS),

3350 La Jolla Village Drive (111N-1),

San Diego, CA 92161, USA

J. E. Bormann

School of Nursing, College of Health and Human Services,

San Diego State University,

San Diego, CA, USA

L. Liu

Department of Family and Preventive Medicine,

University of California San Diego,

San Diego, CA, USA

S. R. Thorp · A. J. Lang

Department of Psychiatry, University of California San Diego,

San Diego, CA, USA

J. E. Bormann $(\bowtie)$

Department of Nursing and Patient Care Services,

VA San Diego Healthcare System,

3350 La Jolla Village Drive (111N-1),

San Diego, CA 92161, USA

e-mail: jill.bormann@va.gov 